Uludag Univ. J. Fac. Vet. Med.

33 (2014), 1,2: 49-55

\title{
Veteriner Anatomi’de Bilgisayar Destekli İllüstrasyon Uygulamaları
}

\author{
Sezin TÜRK KAYA ${ }^{1} \quad$ İlker ARICAN ${ }^{2}$
}

Geliş Tarihi: 06.08.2014

Kabul Tarihi: 16.10 .2014

\begin{abstract}
Özet: Veteriner anatomi, hayvan vücudunun şekil ve yapısını inceleyen bir bilim dalı olarak illüstrasyon yöntem ve tekniklerinden en çok yaralanan bilim dallarından biridir. Veteriner anatomide kullanılan illüstarayonlar, bitkileri, hayvanları ve diğer canlıları tanımlamak için yapılan bilimsel ve teknik illüstrasyonlar içinde değerlendirilir. Son yıllarda yapılan bilimsel illüstrasyon çalışmalarında geleneksel yöntemlerin yanında bilgisayar teknolojisi de kullanılmaya başlanılmıştır. Türkiye'de bilgisayar destekli illüstrasyon çalışmaları sağlık bilimleri alanında da uygulanmaktadır. Ancak veteriner hekimlikte uygulama alanına sahip olmasına rağmen bu alanda yeterli gelişim görülmemektedir.

Bu alana katkı sağlamak amaciyla Uludağ Üniversitesi Güzel Sanatlar Fakültesi Resim Bölümü ve Uludağ Üniversitesi Veteriner Fakültesi Anatomi Anabilim Dalı öğretim üyeleri, 30 Güzel Sanatlar Fakültesi öğrencisi ile fotoğraf ve bilgisayar destekli çalışarak "Köpeğe İçerden Bakmak" başlıklı bir sergi ile sonuçlanan bir çalışma gerçekleştirmiştir.

Çalışma materyali olarak sağlıklı köpeklerin kemik ve iç organları kullanıldı. Seçilen görüntüler Adobe Photoshop ve Adobe Illustrator isimli grafik tasarım programları kullanılarak çizimleri yapıldı. Elde edilen eserler fakültede sergilendikten sonra veteriner anatomi anabilim dalında eğitim materyali olarak kullanıldı.

Ülkemizde alanında ilk örnek olan ve gelecekte bu alanda yapılacak olan çalışmalara önderlik ettiğini düşündüğümüz "Köpeğe İçerden Bakmak" adlı bilgisayar destekli anatomik illüstrasyon çalışması güzel sanatlar eğitimi açısından ve veteriner anatomi açısından değerlendirildiğinde her iki alanın birbirlerini beslediği ve kendi içlerinde gelişmeye katkı sağladıkları sonucuna varılmaktadır.
\end{abstract}

Anahtar Kelimeler: İllüstrasyon, Veteriner Anatomi, Güzel Sanatlar, Bilgisayar.

\section{Computer Generated Illustrations in Veterinary Anatomy}

Abstract: Veterinary anatomy, shape and structure of the animal body as a branch of science which examines the methods and techniques of illustration are one of the sciences that benefit the most from. The illustrations used in veterinary anatomy are assessed as the scientific and technical illustrations that define plants, animals and other creatures. In recent years scientific illustration studies started using computer technologies beside the traditional methods. Computer generated illustration works in Turkey are also carried out in the field of health sciences. However, these studies have application area in veterinary medicine, though development is not considered sufficient.

In order to provide contribution to this area Uludag University Faculty of Fine Arts, Department of Painting and Uludag University Faculty of Veterinary Medicine Department of Anatomy members with 30 fine arts students are performed a study with photographs and computer resulting with an exhibition titled as "Look from inside to the dog".

Bones and internal organs of healthy dogs were used as study specimen. Drawings were made with graphic design programs Adobe Photoshop and Adobe Illustrator from selected images. After being exhibited in faculty, works was forwarded to the department of veterinary anatomy to be used as educational material. 
To the best of their knowledge, "Look from inside to the dog" is unique and pioneer for our country in the field of computer generated veterinary anatomical illustrations. These types of interdiciplinary fine arts and veterinary anatomy studies, when evaluated in terms of both fields that feed off each other and in themselves, contribute to the development is concluded.

Key Words: Illustration, Veterinary Anatomy, Fine Arts, Computer.

\section{Genel Bilgi}

Anatomi, tarih boyu gerek veteriner hekimlik gerekse beşeri hekimlik eğitiminin temel taşlarından biri olmuştur. Anatomi, Yunanca'da "çıkarmak" anlamına gelen "ana" ve "kesmek" anlamına gelen "tome"den türetilmiş bir kelimedir. Canlı vücudunu şekillendiren organların normal şekil, yap1, tabii duruş ve komşu organlarla olan ilişkilerini makroskopik ve subgros olarak inceler. ${ }^{1}$

Sanatçılar da insan ve hayvan anatomisiyle ilgilenmişler, çizimlerini oluştururken bu bilgilerden faydalanmışlardır.

Anatomi eğitiminin görsel materyallerden faydalanmadığı hiçbir safhasının olmadığı göz önüne alınırsa, kaliteli bir eğitimin bir parçası da yeterli bilimsel düzeye sahip illüstrasyondur.

Genel olarak illüstrasyon (Resimleme); kitaplara, yazılı metni açıklamak yada süslemek amaciyla konulan resim olarak tanımlanır. İllüstrasyon, kitabı resimlemenin, süslemenin yanında, metnin anlaşılmasını, akılda kalmasını da sağlar ve yeni bir yorum ekler. ${ }^{5}$ İllüstrasyon kelimesi Latince "lustrate" kökünden türemiştir. "Lustrate" bir şeyi anlaşılır yapmak anlamındadır. ${ }^{4}$ İllüstrasyonu gruplarken reklam, yayın, bilim ve teknik illüstrasyonları olarak genel bir başlık oluşturulabilir. Bitkileri, hayvanları ve diğer canlıları tanımlamak için yapılan öğretici resimler bilimsel ve teknik illüstrasyonlar içinde değerlendirilir.

İllüstrasyon, anatomi bilimi içinde başlangicından bugüne dek etkin olarak yer almakta olan bir sanat dalıdır. İllüstrasyon anatomik yapıları, prosedürleri, ve patolojik durumları açıkça betimlerken, detaydan uzak, gösterilmesi gereken noktalara odaklanmayı sağlayıp, gereksiz ya da dikkat dağıtan unsurları çizimden çıkarir. $^{2}$

Yakın zamana kadar, anatomi öğretiminde diseksiyon ve didaktik anlatım temel öğretim yöntemi olarak kabul edilmekteydi. Günümüzde Öğretim metodolojisinin ve öğrenme kazanımlarının geliştirilmesinde modeller, görüntüleme, simülasyon ve internet devrim olmuştur.
Bilimsel illüstrasyonda geleneksel yöntem olarak, kâğgt, kalem, mürekkep gibi malzemelerden yararlanılmaktadır. İllüstrasyonu yapan kişiler kuru kalem, kuru boya, keçeli kalem, tarama ucu, rapido, suluboya, ekolin, guaj boya veya karışık teknikler kullanabilir. Bütün bu teknikler geleneksel resimleme teknikleridir. ${ }^{2}$

1980’li y1llarda ilk masaüstü bilgisayarların piyasaya sürülmesi ile birlikte 90'lı yıllarda grafik ajansları ve tasarımla ilgilenen serbest sanatçılar çalışmalarını bilgisayar destekli olarak da geçekleştirilmeye başladılar. Bu sürecin devamında 2000'li yıllarda üniversitelerde Güzel Sanatlar Fakültelerinde ve Resim-İş Öğretmenliği bölümlerinde bilgisayar destekli grafik tasarım eğitimleri uygulandı. Son yıllarda yapılan çalışmaların çok büyük bir kısmı bilgisayar ortamında yapılmaktadır.

Bilgisayar donanım ve yazılımlarındaki gelişmeler illüstrasyon sanatında yeni bir araştırma alanı meydana getirerek, sanatçıya klasik tekniklerin veremediği kadar esneklik, detay ve hız kazandırmıştır. Bu güçlü teknoloji, dinamik özellikli, etkileşimli ve görsel gerçekliğe sahip illüstrasyonlar yapmayı da mümkün k1lmaktadır. İllüstrasyonun yoğun olarak kullanıldığ 1 bilim dallarından olan anatomi de bu esneklik ve hızdan faydalanmaya başlamıştır. Kullanılmaya başlanan bilgisayarlı öğrenme paketleri ile anatomi öğretilmesi öğrencilerin uygulama derslerine önceden tam olarak ne beklediğini biliyor olarak gelmesini sağlamakta böylece ders verimliliği artmaktadır. ${ }^{3}$ Diseksiyon odası dışında anatomi öğretiminin geleceği olarak görülen web-tabanlı bilgisayar destekli öğretim kaynaklarına erişen öğrencilerin sınavlarda anlamlı ölçüde yüksek puan aldıkları görülmektedir. $^{6}$

Grafik sanatlar eğitiminde skklıkla kullanılan illüstrasyon teknikleri, son dönemde ağırl1klı olarak bilgisayar destekli şekilde uygulanmaktadır. Türkiye'de de bilgisayar destekli illüstrasyon çalışmalarının sağlık bilimleri alanında uygulanabilirliği son dönemlerde gereklilik halini almıştır. Ülkemizde sağlık bilimleri alanında ihtiyacı karşılamak üzere gerek akademik gerekse serbest çalışan tasarımcılar bu alana ilgi duymaya başlamıştır. 


\section{Köpeğe İçerden Bakmak” Sergisi Üzerine}

Uludağ Üniversitesi Güzel Sanatlar Fakültesi Resim Bölümü ve Uludağ Üniversitesi Veteriner Fakültesi Anatomi Anabilim Dalı, 30 Güzel Sanatlar Fakültesi öğrencisi ile bu alana katkı sağlamak amaciyla fotoğraf ve bilgisayar destekli çalışarak "Köpeğe İçerden Bakmak" başlıklı Anatomik illüstrasyon sergisini gerçekleştirmiştir.

Planlanan çalışmada öncelikle, öğrenciler sağlıklı bir köpeğin kemik yapısı ve iç organları hakkında atlas, fotoğraf ve görsel materyaller eşliğinde Veteriner Fakültesi Anatomi AD Öğretim Üyesi tarafindan teorik olarak bilgilendirildi. Teorik bilgilendirme sonrasında Anatomi Anabilim Dalı Uygulama Salonu'nda bulunan iskelet, kemik, organ ve kadavralar çalışmaya katılan öğrenciler tarafindan öğretim üyeleri eşliğinde fotoğraflandı. Elde edilen fotoğraflardan illüstrasyon amaciyla kullanılacak olanlar seçildi. İllustrasyonların uygulanması aşamasında U.Ü. Güzel Sanatlar Fakültesi Öğretim Üyesi seçilen bölümün hangi programla yapılması gerektiği konusunda öğrenciyi yönlendirdi. Çalışmada yer alan 30 öğrenci 34 farklı illüstrasyon yaptı. Zamanında bitirilen çalışmaların basım süreçleri de kaliteli bir şekilde sonlandı. Çalışmalar yüksek çözünürlüklü yazıcıda suya ve 1sıya dayanıklı forex üzerine basıldı. Eserler Uludağ Üniversitesi Veteriner Fakültesi Hayvan Hastanesinde sergilendi. Sergi sonrasında yap1lan çalışmalar Anatomi Anabilim Dalında öğretim materyali olarak kullanılmaktadır.

Çalışmada illüstrasyonları yapmak için Adobe Illustrator ve Adobe Photoshop programları seçildi. Adobe Illustrator programı vektörel tabanlı bir program olup görüntüler çözünürlükten bağımsızdır. Bu programda her bir nesnenin matematiksel ifadelerle, detay kaybetmeden herhangi bir boyuta yeniden ölçeklendirilebilen nesneler oluşturulabilir. Ortaya çıkan illüstrasyonlarda daha net ve sade biçimler ön plandadır.

Adobe Photoshop programında görüntüler piksel tabanlıdır. Piksel, bir görüntünün yükseklik ve genişlik oranları ile ilgilidir ve basım sonucunu etkileyen önemli bir işleve sahiptir. Adobe Photoshop programında boyama seçenekleri son derece gelişmiştir. Boyama araçları illüstrasyonu yapan kişilere geleneksel malzemelerin (kalem, firça, mürekkep, vb.) etkisini sağlayan seçenekler sunar. Bu sayede programda yapılan illüstrasyonlarda dokusal özelliği daha fazla olan biçimler ön plana çıkmaktadır.
Çalışma sonucu sergilenen illüstrasyonlardan iki farklı programa ait örnek, çalışma süreciyle birlikte ayrıntılı olarak aşağıda sunulmuştur.

\section{Evcil Köpek (Canıs Famıllıarıs) Göğüs Kafesi (Thorax) İllüstrasyonu}

Örnek çalışmada illüstrasyonu gerçekleştirilecek bölge olarak köpeğin (canis familliaris) gögüs kafesi (thorax) seçildi. (Şekil 1) Bu bölgede yapılan illüstrasyon çalışmasında vektörel bir program olan Adobe Illustrator CS6 programını kullanıldı. Çizim yapmak için program menüsünden seçilen araç, "Dolma Kalem/ Pen Tool” arac1 tercih edildi. Araç, programda simgesiyle yer alır. Aracın alt menüsü çalışılacak alan ya da dokunun özelliğine göre seçilen açık ya da kapalı alan alternatifleri sunmaktadir. ${ }^{7}$ a)

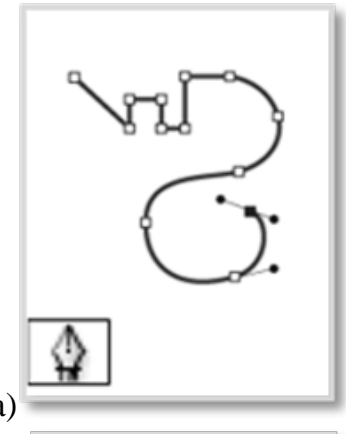

c)

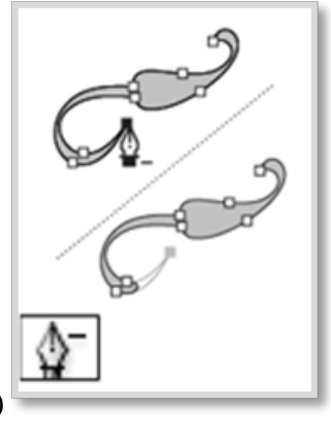

b)

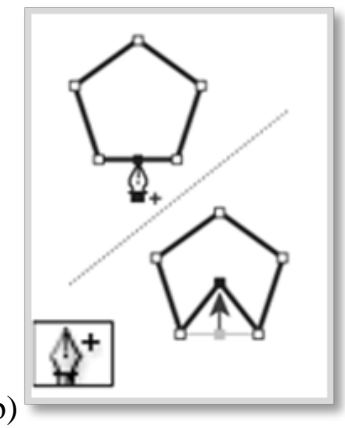

d)
Şekil 1. a) Pen Tool/ Dolma Kalem aracı nesne oluşturmak üzere düz ve eğri çizgiler çizer. b) Add Anchor Point Bağlantı Noktası Ekleme aracı, yollara bağlantı noktaları ekler. c) Delete Anchor Point Bağlantı Noktası Silme aract, yollardan bağlantı noktalarını siler. d) Convert Anchor Point Bağlantı Noktası Dönüştürme aracı yumuşak noktaları köşe noktalarına dönüştürür.(7)

Figure 1. a) The Pen Tool (P) draws straight and curved lines to create objects. $b$ ) The Add Anchor Point tool (+) adds anchor points to paths. c) The Delete Anchor Point tool (-) delete anchor points from paths. d) The Covert Anchor Point tool (Shift $+C$ ) changes smooth points to corner points and vice versa. 
Açık yol, düz veya eğri çizgiler oluşturulduğunda tercih edilir (Şekil 1a). Başlangıç noktasında sona eren alanların oluşturulması kapalı yol örneğidir. Açık ya da kapalı yolun ana gidiş hattı kontur olarak adlandırılır. Konturun kalınlığ 1 ve rengi değişkendir. Oluşturulan bir yolun kontur kalınlığ ve kapalı alanın dolgu renkleri sonradan değişebilir. Bu özellikler yapılan tasarımların farklı alternatifler de değerlendirilerek kısa sürede tamamlanmasına olanak sağlamaktadır. ${ }^{8}$

Çalışmanın başlangıç aşamasında öğrenciye farklı kemikler gösterildi. Bu kemikler içinden ortak bir renk seçmesi istendi. Seçtiği bu renk üzerinden açık renkte olması gerek yerleri belirlediği rengin açık tonunu kullanarak, koyu renkte olması gereken yerleri seçtiği rengin koyu tonlarını kullanarak yaptı. Örnek çalışmada eğri çizgiler daha çok kullanıldı. (Şekil 2)

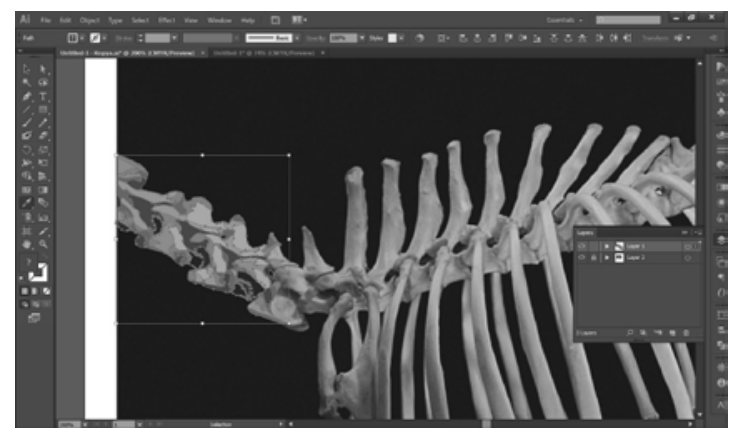

Şekil 2. Kapalı Yol Uygulamast

Figure 2. Path practice

Köpeğin sol tarafından başlayan kapalı yollar kullanarak oluşturulan çalışmada yapılan yerler noktalı seçim alanı ile gösterildi (Şekil 3). $\mathrm{Bu}$ aşamada öğrenci seçili alan içerisinde dolgu rengi kullanmamaktadır. Noktalı çizgi ile gösterilen uygulama alanlarına tasarımı yapan öğrenci tarafından kontrol etmek için seçim işlemi uygulandı. Parça parça ilerleyen çalıșmada tüm alanlar aynı yöntem izlenerek çalışılarak tamamland1. (Şekil 4)

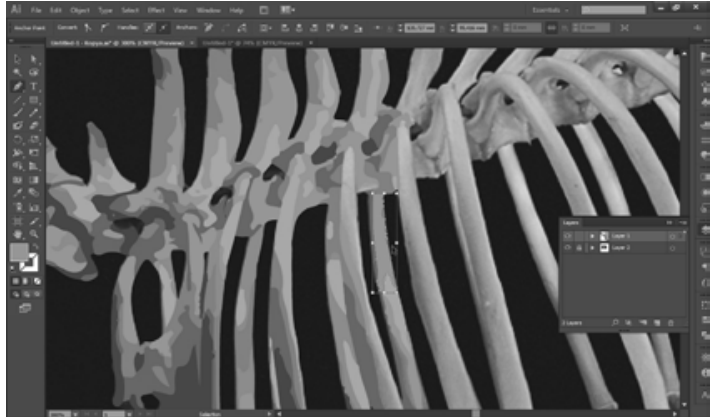

Şekil 3. Alan seçimi kapalı yol

Figure 3. Selecting path segment

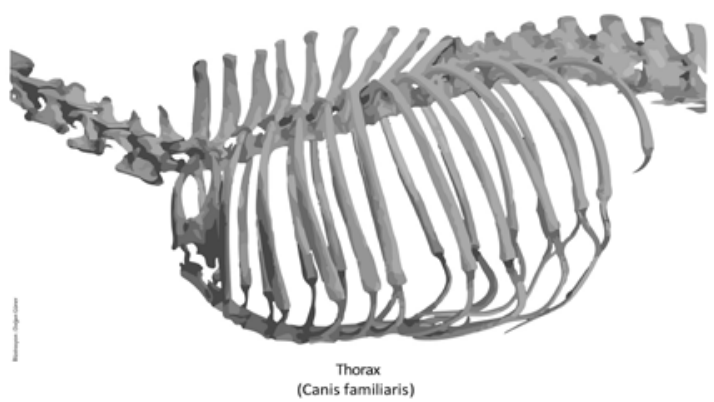

Şekil 4. Çalıșma sonlandırıldı ̆̆ında. Illiüstrasyon: Doğan Güner

Figure 4. Finalised work Illustrator: Doğan Güner

\section{Evcil Köpekte Karın Boşluğunun (Cavum Abdomınıs) Soldan Görünümü}

Örnek çalışmada illüstrasyonu gerçekleştirilecek bölge olarak köpeğin (canis familliaris) karın boşluğu ve iç organları seçilmiștir (Şekil 5). Çalışmaya başlamadan önce öğrenciye anatomi uygulama salonunda organların normal dokusu gösterildi. Bu illüstrasyon çalışmasında pixel tabanlı bir program olan Adobe Photoshop CS6 programını kullanıldı. Program menüsünde boyama araçlarının başında firça araçları \&, kalem arac1 \& , silgi aracı, leke aracı gibi araçlar gelir. Öğrenci photoshop programında boya ve kalem araçları ile dijital boyama yaparak çalışmayı gerçekleştirdi. Çalışmanın daha verimli ve değişikliğe açık olması açısından görüntüde yer alan iç organlar farklı katmanlara çalıșıldı. Photoshop programında yer alan katman (layer) özelliği bu çalışmada aynı bölgeyi farklı renklerde boyama ve öne arkaya getirme seçenekleri ile öğrenciye avantaj sağladı. Öğrenci renk seçimi yaparken veteriner anatomi ile ilgili illüstüratörlerin genel olarak kullandıkları renkleri çalışmasında tercih etti. Bu kullanımda atardamarlar (arter) kırmızı, toplardamarlar (vena) mavi, sinirlerde ise sarı rengin kullanımı tercih edilmektedir. ${ }^{9}$ 


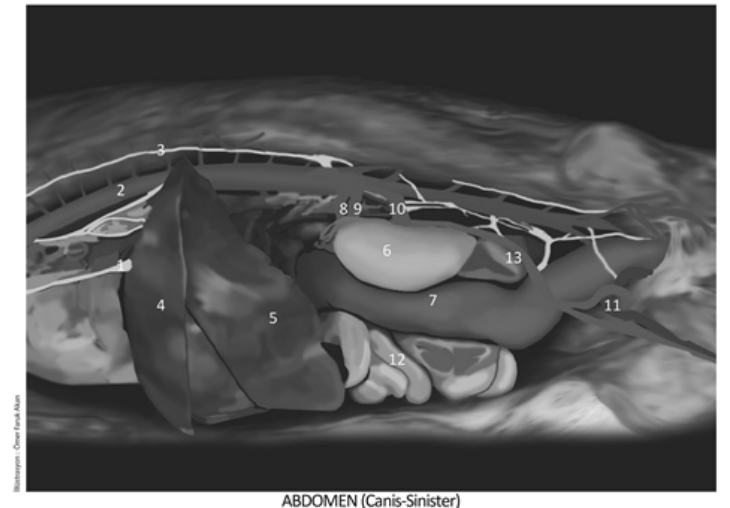

1.N. phrenicus 2.Aorta descendens 3.Tr. sympathicus 4.Diaphragma 5. Hepar 10.A. renalis 11.Ductus deferens 12.Jejenum 13. Ureter
(Canis familiaris)

Şekil 5. Köpeğin İç Organları, Illlüstrasyon: Ömer Faruk Akan

Figure 5. Internal organs of the dog, Illustrator: Ömer Faruk Akan

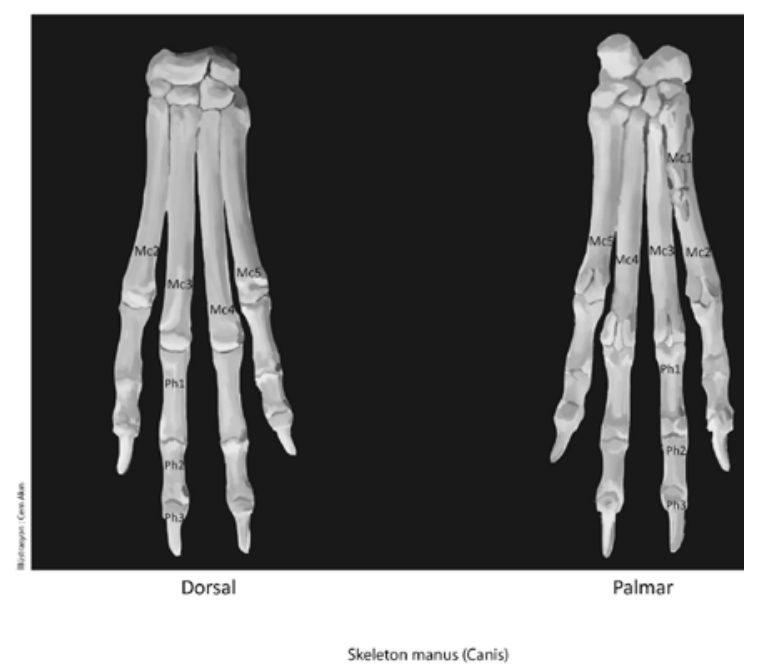

Şekil 6. Ön ayak iskeletinin AI6 ile dijital İllüstrasyonu, Illüstratör: Cem Akın

Figure 6. Digital illustration of the Skeleton of the dog manus with AI6, Illustrator: Cem Akın

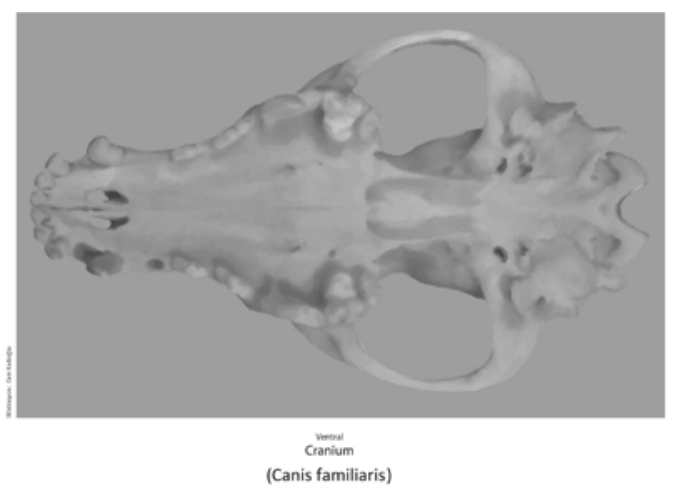

Şekil 7. Köpek kafatasının PS6 ile dijital illüstrasyonu, Illü̈strasyon Cem Kadıoğlu

Figure 7. Digital illustration of the cranium of the dog with PS6, Illustrator: Cem Kadıoğlu

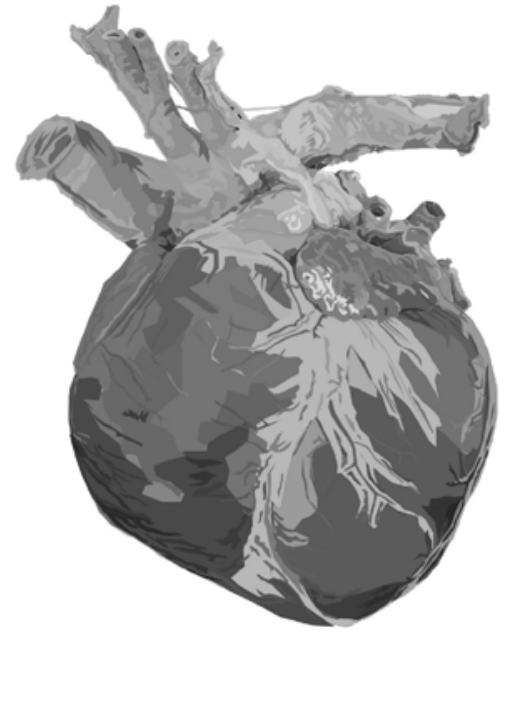
COR-Facies auricularis
(Canis familiaris)

Şekil 8. Köpek kalbinin AI6 ile dijital İllüstrasyonu, Illü̈strasyon Gülşah Çalhan

Figure 8. Digital illustration of the heart of the dog with AI6, Illustrator: Gülşah Çalhan

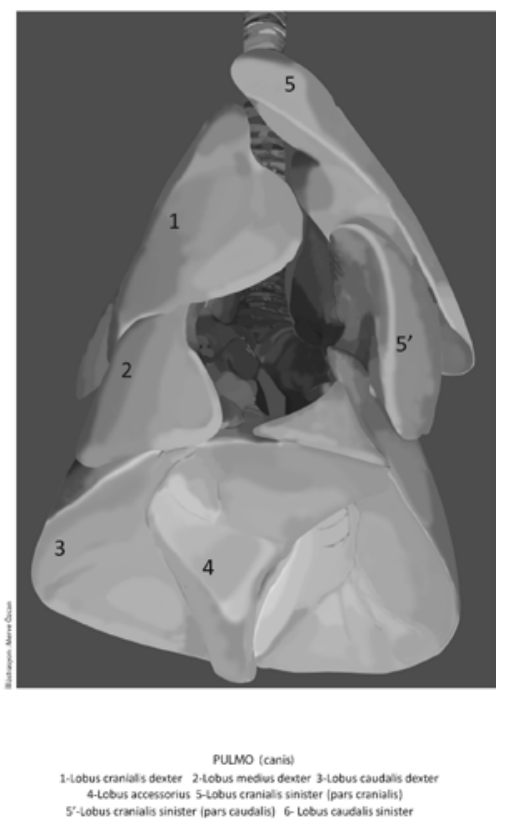

Şekil 9. Köpek akciğerinin PS6 ile dijital illüstrasyonu, Illüstrasyon Merve Özcan

Şekil 9. Digital illustration of the lung of the dog with PS6, Illustrator: Merve Özcan 


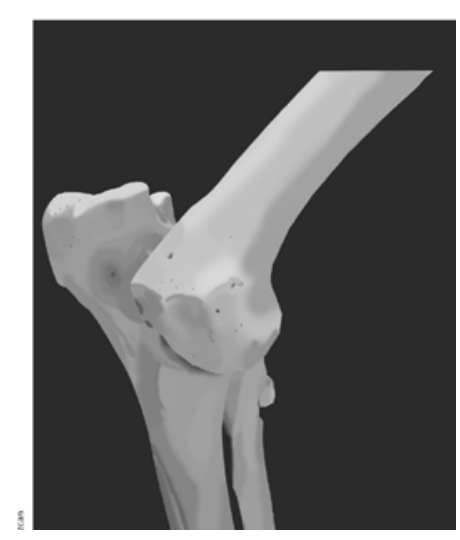

Şekil 10. Köpek dirsek ekleminin PS6 ile dijital illüstrasyonu, İllüstrasyon Merve Özcan

Figure 10. Digital illustration of the skeleton of the dog cubitus with PS6, Illustrator:

\section{Merve Özcan}

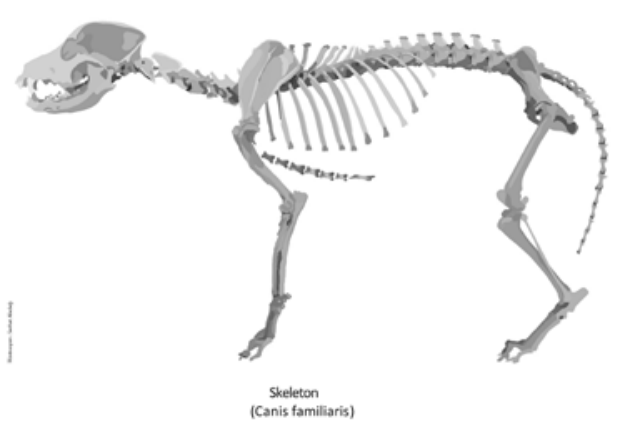

Şekil 11. Köpek iskeletinin AI6 ile dijital İllüstrasyonu, Illü̈strasyon Serhat Alada $\breve{g}$

Figure 11. Digital illustration of the skeleton of the dog with AI6, Illustrator: Serhat Aladağ

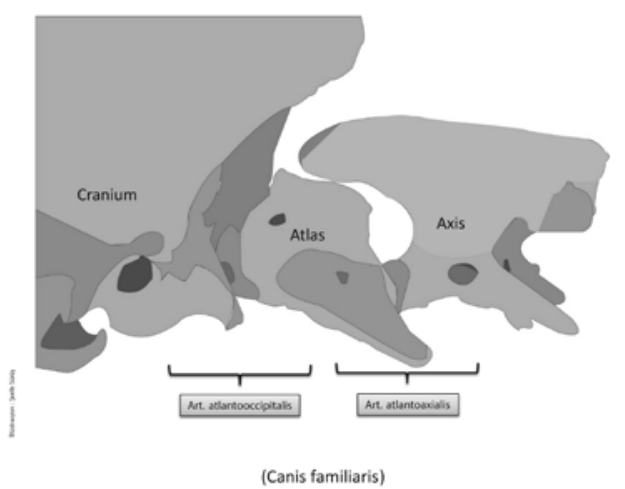

Şekil 12. Köpek kafatast, atlas ve axis 'in eklemleşmesinin AI6 ile dijital İllüstrasyonu, İllüstrasyon Şerife Suruş

Figure 12. Digital illustration of the articulation of the cranium, atlas and axis with AI6, Illustrator: Şerife Suruş
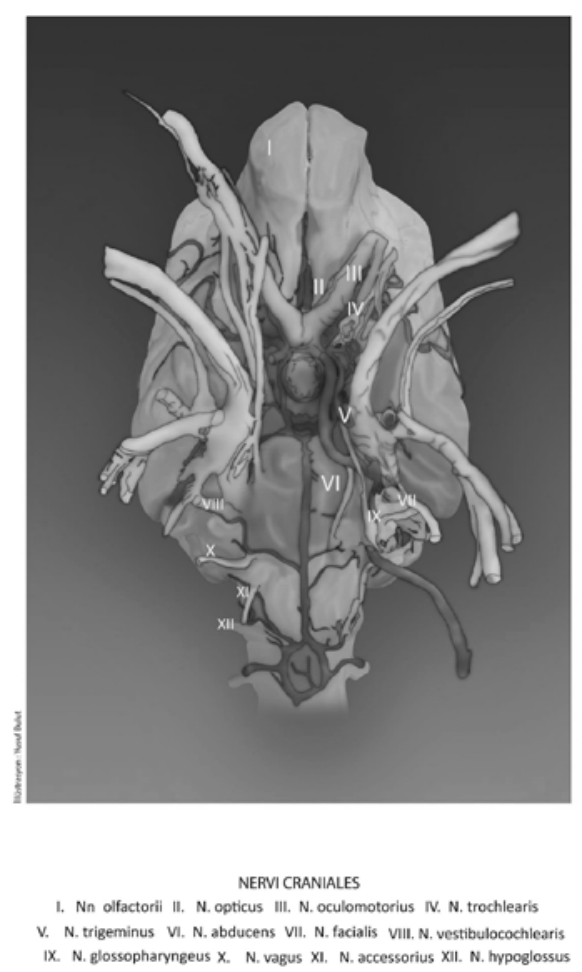

Şekil 13. Köpeğin 12 çift beyin sinirlerinin PS6 ile dijital illüstrasyonu Illlüstrasyon Yusuf Bulut

Figure 13. Digital illustration of the cranial nerves with PS6, Illustrator: Yusuf Bulut

\section{Sonuç}

Dijital dünya tüm alanlarda olduğu gibi eğitim öğretim alanında da geniş üretim olanakları sağlamakta ve her geçen gün sunduğu olanakları da geliştirmektedir. Gerek veteriner anatomi gerekse güzel sanatların bu olanaklardan yararlanması da kaçınılmazdır. Çalışma ile illüstrasyonun anatomide kullanımı hakkında genel bilgiler aktarılmış, anatomist ve illüstratör arasındaki etkileşimin ana hatlarını ortaya konulmuştur.

Ülkemizde Veteriner hekimlikte ve özellikle çalışmamızın konusu olan anatomide bilgisayar destekli illüstrasyonun kullanımının irdelenerek bilimsel platforma taşınması bir gereklilik haline gelmiştir. Anatomi ve sanatsal çevrelerin konuya ilgisinin artması her iki dal için de faydalı olacak bir işbirliği ile sonuçlanacaktır.

Dünyada veteriner hekimliği alanında da bilimsel illüstrasyon çalışmaları bulunmaktadır. Aynı zamanda bu eserlere kitaplardan ya da internet ortamında ulaşılması mümkündür. Ancak Türkiye'de veteriner hekimliği alanında bilimsel illüstrasyon yapan tasarımcı sayıs1 yeterli olmadığ gibi ders kitaplarının hazırlanmasında yararlanılacak özgün profesyonel eser 
sayısı da yeterli değildir. Bir sergi ile sonuçlandırılan köpeğe içerden bakmak isimli çalışma sayesinde güzel sanatlar fakültesi öğrencileri bilimsel illüstrasyonla tanışmış ve özgün eserler üretmişlerdir. Çalışma sürecinde bazı öğrencilerin bu alan için yetenekli oldukları görülmüş olup, bilimsel illüstrasyon alanında potansiyel tasarımcı olabilecekleri ön görülmektedir.

Ülkemizde alanında ilk örnek olan "Köpeğe İçerden Bakmak" adlı bilgisayar destekli anatomik illüstrasyon çalışması güzel sanatlar eğitimi açısından ve veteriner anatomi açısından değerlendirildiğinde her iki alanın birbirlerini beslediği ve kendi içlerinde gelişmeye katkı sağladıkları sonucuna varılmaktadır. Güzel sanatlar fakültesi öğrencilerinin illüstrasyonun oluşumunun her aşamasında var olması bilimsel bir illüstrasyonun nasıl yapıldığı konusunda tecrübe sahibi olmasını sağlarken, veteriner fakültesi öğrencileri için de ortaya çıkarılan ürünler veteriner anatomi öğretimine katkıda bulunacaktır. Bununla birlikte ortaya çıkarılan bu eserler gelecekte ders kitaplarında konuyu destekleyen özgün illüstrasyonlar olarak kullanılabilmelerinin yanında bir animasyon ya da interaktif bir eğitim materyaline dönüştürülebileceklerdir.

\section{Kaynaklar}

1. BAHADIR A, YILDIZ H. Veteriner Anatomi I, Hareket Sistemi, ISBN: 975-8606-37-9, Ezgi Kitabevi, Bursa, 2004.

2. Becer, E., 1999, İletişim ve Grafik Tasarım, Dost Kitabevi, Ankara, 211.

3. Collins JP. 2008. Modern Approaches To Teaching And Learning Anatomy. BMJ 337:a1310.

4. Dağ Songür E., 2011, İllüstrasyonda Alternatif Diller: Bulunutu Nesneler İle İllüstrasyon, Grafik Tasarım Dergisi, 45, 84-85)

5. Keser. N., 2009, Sanat Sözlüğü, Ütopya Yayınevi, Ankara,167.

6. McNulty JA, Sonntag B, Sinacore JM. 2009. Evaluation Of Computer-Aided Instruction In A Gross Anatomy Course: A six-year study. Anat Sci Educ 2:2-8.

7. İllüstratör Araç Galerileri, Çizim Aracı Galerisi, http://help.adobe.com/tr_TR/illustrator/cs/using/ WS14386A18-6B9B-436d-8FF1B98770564424.html\#WSD9D32F96-7F5C-4153948C-AE9C4F5797F1a

8. İllüstratör/ Çizim Hakkında Genel Bilgiler http://help.adobe.com/tr_TR/illustrator/cs/using/ WS714a382cdf7d304e7e07d0100196cbc5f6269a.html\#WS5D46593F-4593-4f0c-A23F81B9509450F2

9. Photoshop Yardımı / Boyama Araçları https://helpx.adobe.com/tr/photoshop/using/painti ng-tools.html 
